\title{
EL PASADO Y SUS ENEMIGOS. SOBRE LA INACTUALIDAD DE LO CONTEMPORÁNEO ${ }^{1}$
}

\author{
DOMINGO HERNÁNDEZ SÁNCHEZ
}

Universidad de Salamanca

\begin{abstract}
RESUMEN: Este artículo trata de examinar el significado actual de las heterocronías, los anacronismos y otras interrupciones del tiempo histórico. Se intenta con ello investigar qué sucede cuando el material de la historia, es decir, la memoria y el pasado, se convierten en pura actualidad al transmitirse mediante todo tipo de versiones y reciclajes culturales. El objetivo final es distinguir entre un pasado que sólo permite su recuerdo y otro en el que, peligrosamente, parece que se recuerda mientras se percibe.
\end{abstract}

PALABRAS CLAVE: historia; anacronismo; contemporáneo; pasado; memoria.

\section{The past and its enemies. On the Inactualities of the Contemporary}

ABSTRACT: This article examines the contemporary meaning of heterochronies, anachronisms, as well as other interruptions of historical time. The aim is to explore what happens when the matter of history, that is, memory and the past, turn into actualities conveyed through all kinds of versions and cultural spin-offs. The ultimate objective is to distinguish between a past that only allows its remembrance and another one that dangerous is remembered as it is perceived.

KEY WORDS: history; anachronism; contemporary; past; memory.

Situadas en determinado contexto, qué curioso significado adquieren hoy las palabras de Hegel. Me refiero a las más conocidas en el ámbito de la estética y la filosofía del arte, las más clásicas, aquellas según las cuales el arte, tomado en su determinación más alta, es "für uns ein Vergangenes» ${ }^{2}$. La traslación puede parecer demasiado forzada y la descontextualización excesivamente obvia, por supuesto, pero el hecho es que ante el cúmulo de reciclajes, remakes y demás retromanías, a veces da la impresión de que todo, incluido el futuro, parece ser a día de hoy cosa del pasado. Es un fenómeno que discurre en un contexto mucho más amplio que el del arte, claro está, pues atraviesa machaconamente la cultura contemporánea, de un modo especial aquella que hace algún tiempo denominábamos «cultura de masas». Resulta así comprensible que sean las propias prácticas artísticas actuales quienes, casi a la contra, deseen adecuarse al tiempo «en la forma de una demanda de contemporaneidad», como afirma Peter Osborne ${ }^{3}$. Y es que seguramente sea

1 Este trabajo se integra en los resultados del Proyecto de Investigación FFI2016-76891C2-2-P -Agencia Estatal de Investigación (AEI) del Ministerio de Economía, Industria y Competitividad y el Fondo Europeo de Desarrollo Regional (FEDER) de la Unión Europeay del Proyecto de Investigación 463AC01 —Universidad de Salamanca, Programa 1C, 20172019-.

2 Hegel, G. W. F., Filosofía del arte o Estética. Verano de 1826, ed. bilingüe de A. Gethmann-Siefert y B. Collenberg-Plotnikov, trad. de Domingo Hernández Sánchez, Madrid, Abada Editores / UAM Ediciones, 2006, p. 60.

3 Osborne, P., El arte más allá de la estética, trad. de Y. Hernández, J. Furió y A. García, Murcia, Cendeac, 2010, p. 257. 
aquí, en tal solicitud de contemporaneidad, donde haya de moverse el nuevo significado asumido por las cosas del pasado.

En efecto, quizá sea en este punto donde deba iniciarse el desarrollo, en la relación entre lo contemporáneo y lo actual, y en cierta necesidad de pasado. Acudir, en este sentido, a Giorgio Agamben, parece casi obligado, sobre todo por la rotundidad de sus interrogaciones: «¿De quién y de qué somos contemporáneos? Y, sobre todo, ¿qué significa ser contemporáneos?», escribe. Demandar contemporaneidad en las prácticas artísticas y, a la vez, preguntarnos por el significado de lo contemporáneo: ése parece ser el problema, el de la necesidad de exigir algo que, ahora, no sabemos muy bien qué significa, pero que ineludiblemente somos, o deberíamos ser. Para Agamben, "pertenece en verdad a su tiempo, es en verdad contemporáneo, aquel que no coincide a la perfección con éste ni se adecúa a sus pretensiones, y entonces, en este sentido, es inactual; pero, justamente por esto, a partir de ese alejamiento y ese anacronismo, es más capaz que los otros de percibir y aferrar su tiempo». Son la inactualidad y el anacronismo los que parecen permitir al contemporáneo ser contemporáneo, los que le conceden el desfase y la distancia necesarios para aferrar su tiempo desde una mirada que elude la coincidencia plena con la época y, por tanto, "no se deja cegar por las luces del siglo y es capaz de distinguir en ellas la parte de la sombra, su íntima oscuridad» ${ }^{4}$.

Demasiada actualidad aleja de lo contemporáneo, en tanto impide ver las oscuridades que hay que interpelar, ésas que verdaderamente nos incumben y han de descubrirse entre la extrema luminosidad de lo actual. No ha de extrañar, entonces, que Peter Osborne demandara contemporaneidad. Y es que «los contemporáneos son raros; y por eso ser contemporáneos es, ante todo, una cuestión de coraje» ${ }^{5}$. Coraje para ser capaz de moverse entre luces y sombras, de adecuarse a las temporalidades entrelazadas cuyo despliegue permite configurar la arqueología que conduce hasta el presente. Una arqueología también especial, por cierto, pues no remite a pasados remotos, sino a lo no-vivido en el presente, a la pura potencialidad, a eso que, cegados por las luces de la actualidad, no hemos sabido ver $\mathrm{y}$, por tanto, no hemos podido vivir: «La atención a ese no-vivido es la vida del contemporáneo. Y ser contemporáneos significa, en ese sentido, volver a un presente en el que nunca estuvimos» ${ }^{6}$. No dejan de ser, también, palabras extrañas éstas, por lo menos a primera vista: ¿lo no-vivido en lo vivido?, ¿se trata de actualizar cierta espectralidad, cierta hauntología caracterizada por la nostalgia de lo que pudo ser? Y, del otro lado, ¿un presente en el que nunca estuvimos?, ¿no es eso algo muy cercano a la definición del déjà vu?

Sea como sea, el hecho es que la defensa de la inactualidad y el anacronismo como posibilidad para pensar el presente y, por tanto, acceder a la contemporaneidad, se apoya sin ocultarlo en una base concreta. Una base que, todo sea dicho, tras la multitud de investigaciones dedicadas al tema de la memoria, parece haberse convertido en un lugar común, desgastado con tanta cita y comentario superfluo. Me refiero, claro, a la segunda de las Consideraciones intempestivas, Sobre la

4 Agamben, G., "¿Qué es lo contemporáneo?», en Agamben, G., Desnudez, trad. de M. Ruvituso y M. ${ }^{\text {a }}$ T. D’Meza, Barcelona, Anagrama, 2011, p. 17, p. 18 y p. 21, respectivamente.

5 Agamben, G., «¿Qué es lo contemporáneo?», ed. cit., p. 22.

6 Ibid., p. 26. 
utilidad y el perjuicio de la historia para la vida. Sea para defender la importancia del olvido, sea para subrayar la hipertrofia de la memoria — del sentido histórico, diría Nietzsche-, lo cierto es que acudir a la segunda de las Intempestivas se ha convertido en cliché. "He llegado a tener tales experiencias intempestivas como hijo de este tiempo actual ${ }^{7}$, escribía Nietzsche, y es lo que solicita Agamben. También Osborne insistía en que "lo contemporáneo aparece como "heterocrónico": un tiempo "anormal” de ocurrencias irregulares, o en términos nietzscheanos, un tiempo “intempestivo” »". En todo caso, si aquí aparecen contextualizadas en torno a la idea de lo contemporáneo, no sería difícil hallar muchas otras presencias intempestivas en los estudios recientes sobre la memoria y su peso. $\mathrm{O}$, dicho de otra manera: que, en su defensa de la inactualidad, Agamben resulta de lo más actual. Tanto que su artículo ha sido recuperado por autores como Georges Didi-Huberman en Supervivencia de las luciérnagas o Hans Ulrich Obrist en su «Manifiestos para el futuro»?.

Y, sin embargo, la sutil defensa que hace Agamben del anacronismo y la inactualidad para acceder a lo contemporáneo, no debería entenderse únicamente en torno a esa, a veces agotadora, presencia de las intempestivas nietzscheanas. No se trata sólo de incidir en esta curiosa actualidad de la inactualidad, sino que quizá fuera conveniente ampliar el marco de acción y redirigir las tesis de Agamben hacia un contexto conocido y bien trabajado en los últimos años: el de la venganza del anacronismo - alguna vez calificado como «el pecado de los pecados» en historia-; el del éxito, a la contra, del anacronismo en los discursos sobre la memoria y el pasado a fin de pensar el presente, hasta el punto de tener todos más o menos claro que «no se puede aceptar la dimensión memorativa de la historia sin aceptar, al mismo tiempo, su anclaje en el inconsciente y su dimensión anacrónica» ${ }^{10}$. Y no es necesario remitir a la casi ineludible presencia de esos autores que Didi-Huberman situaba en la «constelación anacrónica»: Walter Benjamin, Carl Einstein y Aby Warburg ${ }^{11}$. No, no es necesario, todavía, servirnos de tales pensadores intempestivos, anacrónicos ya en su tiempo y, quizá por ello, terriblemente actuales hoy. En su lugar, es posible acudir a lo que podría entenderse como la moda del anacronismo, moda muy posmoderna al comienzo, claro está, y perfectamente coherente en su momento para contrarrestar cierta gestión del pasado y de la memoria, y, con ellos, de la historia en su conjunto, de un modo especial, por supuesto, la del arte.

No faltan nombres y títulos que, por citar sólo algunos, constituirían un camino cuyo discurrir se iniciaría en aquellos artículos de los ya tan lejanos años noventa —el de Nicole Loraux, «Éloge de l'anachronisme en histoire» (1993); el de Jacques Ranciere, «Le concept d'anachronisme et la verité de l'historien» (1996); el de

7 Nietzsche, F., Sobre la utilidad y el perjuicio de la historia para la vida [II intempestiva], ed. y trad. de G. Cano, Madrid, Biblioteca Nueva, 1999, p. 39.

8 Osborne, P., El arte más allá de la estética, ed. cit., p. 268.

9 Respectivamente, Didi-Huberman, G., Supervivencia de las luciérnagas, trad. de J. Calatrava, Madrid, Abada Editores, 2012, p. 53 ss., у OвRIST, H. U., «Manifestos for the Future», e-flux Journal, 12, enero 2010.

10 Didi-Huberman, G., Ante el tiempo. Historia del arte y anacronismo de las imágenes, trad. de O. A. Oviedo Funes, Buenos Aires, Adriana Hidalgo Editora, 2006, p. 41.

${ }_{11} \quad$ Ibid., pp. 52-58. 
Hans Magnus Enzensberger, «Vom Blätterteig der Zeit. Eine Meditation über den Anachronismus»(1996)_, atravesaría al Paolo Virno de Il ricordo del presente. Saggio sul tempo storico (1999) y llegaría, claro, al propio Georges Didi-Huberman y los textos mencionados de Agamben o Peter Osborne. Quizá fuera éste el relato más propicio para ubicar el discurso del filósofo italiano. Y, sin embargo, situado en ese contexto, vuelven a surgir las interrogaciones... y los fantasmas. "La disyunción en la presencia misma del presente, esa especie de no contemporaneidad consigo mismo del tiempo presente (esa intempestividad o anacronía radicales a partir de las que intentaremos, aquí, pensar el fantasma)...», escribía Derrida en Espectros de $\operatorname{Marx}^{12}$. No extraña que la historiografía de corte clásico huya de los anacronismos: a nadie le gusta vivir entre espectros y demás resucitados. Pero, ¿y si exactamente ésa fuese la situación actual? ¿Y si aquella "historia de fantasmas para adultos» ${ }^{13}$, como definía Warburg en 1928 la historia de las imágenes que él practicaba, hubiese adquirido un significado generalizado? La aparición, aquí, de Derrida, no es casual, aunque no se debe, o, por lo menos, no sólo, a sus fantasmas y espectros, a los suyos o a los de Marx. Su intromisión responde más bien al deseo de enfatizar la epocalidad y tipología del discurso sobre los anacronismos: por lo menos en sus inicios, se trata de un discurso muy años noventa, muy marcado por el posmodernismo de la década anterior, más que afianzado entre todo tipo de discontinuidades, déjà vues, temporalidades out of joint y demás «burlas de la memoria ${ }^{14}$.

Ahora bien, la rehabilitación del anacronismo ha continuado su proceso modificando su sentido de forma paulatina y sutil. Y lo ha hecho, precisamente, a partir del momento en que su propio marco de acción, el de esa posmodernidad que lo contextualizaba, ha sido devorada por lo que podríamos llamar su configuración más exacta: la de una tecnología, en este caso, evidentemente, Internet. Como dice Simon Reynolds en Retromanía, la terminología usada para definir eso que se supone más allá del posmodernismo, etiquetas como «superhibridez», «digimodernismo»o, incluso, la "postproducción» de Bourriaud, no son más que intentos de «completar la ecuación “posmodernismo + Internet $=$ ?” ${ }^{15}$. Nos hallamos así, una vez más, ante la posibilidad de asistir en directo al espectáculo de cómo una tecnología devora una teoría. En los términos de Reynolds, el argumento sería el siguiente: «En el número de Frieze dedicado a la super-hibridez, Jennifer Allen sostenía que Internet hizo que el posmodernismo quedara obsoleto como estrategia artística, asimilando sus principios, volviéndolos ubicuos y accesibles a todos, naturalizándolos de tal modo que hoy componen la trama de la vida cotidiana. Una teoría fue reemplazada "por una tecnología que hacía el mismo trabajo con mayor eficiencia". Como dijera Seth Price en el mismo número de la revista: "con Internet, la cantidad de material disponible se acerca al infinito, y usar agresivamente materiales dispares ya no

12 Derrida, J., Espectros de Marx. El Estado de la deuda, el trabajo del duelo y la nueva Internacional, trad. de J. M. Alarcón y C. de Peretti, Madrid, Trotta, 1995, pp. 38-39.

13 Didi-Huberman, G., La imagen superviviente. Historia del arte y tiempo de los fantasmas según Aby Warburg, trad. de J. Calatrava, Madrid, Abada Editores, 2009, p. 79.

14 BodeI, R., Pirámides de tiempo. Historias y teoría del déjà vu, trad. J. A. Méndez, Valencia, Pre-Textos, 2010, p. 18.

15 Reynolds, S., Retromanía. La adicción del pop a su propio pasado, trad. de T. Arijón, ed. de P. Schanton, Buenos Aires, Caja Negra, 2012, p. 427. 
implica sacar las cosas de contexto, porque ya hubo alguien que previamente dio ese paso por nosotros" ${ }^{16}$. Aunque Reynolds se refiere especialmente a la retromanía en términos musicales, es decir, a la obsesión por el pasado de la música actual, no es difícil vincular todos los contextos.

Y es que, en el fondo, ésta es la principal cuestión a esclarecer: la de cómo acceder al anacronismo y sus caracteres principales en la época de la retromanía; la de cómo, y para qué, seguir defendiendo el anacronismo como ruptura e interrupción cuando casi puede afirmarse que una parte considerable de la escena cultural es ya pura gestión de la inactualidad y el anacronismo; la de cómo entender un gesto como el anacrónico, insatisfecho e inconformista con lo transmitido, y lo reprimido, cuando «el inconformismo es la sangre vital de la sociedad de consumo» ${ }^{17}$. En todo caso, si se tiene en cuenta que quizá una de las claves se encuentre en la relación con lo ya visto, o lo ya escuchado, es importante modificar levemente los referentes.

Es bien sabido que el déjà vu ha sido utilizado, de modo casi obsesivo, como imagen representativa en teorías fundamentales sobre la cultura y las sociedades contemporáneas. Su misión tenía un objetivo claro: definir esa situación, tan cotidiana, en la que el presente se desprende de su espontaneidad para transformarse en extraña, fantasmática repetición de lo sucedido. "Lo déjà vu se ha convertido en nuestra regla de lugar, tiempo y verdad», escribía Hillel Schwartz en un libro tan posmodernamente correcto como La cultura de la copia ${ }^{18}$. Aunque más adelante recurriremos a la que quizá sea la más interesante de las teorías del déjà vu, la de Paolo Virno, es posible afirmar ya que ese déjà vu, o déjà écouté, actualmente habría sido sustituido por un fenómeno relacionado, aunque mucho menos atractivo: el presque vu, nuestro «tener en la punta de la lengua». Así, la sensación ante una parte importante de fenómenos culturales vigentes no sería la de «esto creo haberlo visto -o escuchado, o leído- ya", sino la de "no me sorprende demasiado: casi lo recordaba, casi lo había visto, casi lo había escuchado». Cierta dictadura de lo previsible, entonces, que coloca a los anacronismos en una difícil situación al confinarlos en un reducido espacio acosado por la actualidad de lo inactual, de un lado, y, del otro, la urgencia de la innovación, esa necesidad de primicia y suceso que, en demasiados casos, confluye en lo que podríamos denominar — con alusión obvia - una angustia de las ocurrencias. Sea como sea, el hecho es que las parejas comienzan a concretarse: de una parte, anacronismo y déjà vu; de la otra, retromanía y presque vu. También lo hacen sus estrategias: el misterio y la sorpresa inherentes a la primera han de lidiar con la recuperación de un pasado comprensible, tranquilo, todo menos enigmático, de la segunda.

En efecto, seguramente sea tal ausencia de misterio la verdadera protagonista. La «extrañeza alucinatoria» del pasado, que estudiaba José A. Zamora en un detallado

16 Reynolds, S., Retromanía, ed. cit., pp. 427-428. El número de Frieze al que alude es el 133, de septiembre de 2010, enmarcado bajo el interrogativo Super-hybridity?

17 FRANK, T., La conquista de lo cool. El negocio de la cultura y la contracultura y el nacimiento del consumismo moderno, trad. de M. Sumoy y J. C. Castillón, Barcelona, Alpha Decay, 2011, p. 375.

18 Schwartz, H., La cultura de la copia. Parecidos sorprendentes, facsímiles insólitos, trad. M. Talens, Madrid, Cátedra, 1998, p. 306. 
artículo sobre el tiempo en Walter Benjamin ${ }^{19}$, sería la que habría desaparecido. Y es que, ahora, el trapero de Benjamin, ese personaje para el que «todo es anacronismo porque todo es impuro ${ }^{20}$, ese historiador que trabajaba mediante la erudición en la impureza y los desechos del tiempo, ha modificado sus herramientas y modos de acceso: por un lado, ya no tiene que rebuscar incansable y, a veces, infructuosamente en los basureros de la historia, sino que ahora puede hacerlo tranquilamente desde cualquier motor de búsqueda en Internet, con imagen y sonido incluidos; por el otro, si aun así desea seguir rebuscando de modo real, que no se preocupe: se le llamará hipster y su problema no será encontrar las grietas de la memoria, sino evitar convertirse en un simple adicto al pasado que juguetea con lo retrochic. Es el efecto de lo que Reynolds llama década re-, cronológicamente enmarcada en los primeros diez años del siglo XXI y definida a partir de todo tipo de revivals, reediciones, remakes, reciclajes, retornos, revisitaciones y demás modas vintage. Algo comprensible, en todo caso, si tenemos en cuenta que la década precedente, la de 1990, fue «la década en la que se asistió en el mundo entero a una explosión sin precedentes de la cultura de la memoria ${ }^{21}$. No resulta demasiado complicado, entonces, afirmar que uno de los resultados de esa explosión es, precisamente, el nacimiento de la década re-.

Ahora bien, aunque los cambios, y conexiones, producidos en el paso de una década, la última del siglo XX — la de la explosión de la memoria, la del anacronismo y el déjà $v u$ - a otra, la primera del siglo XXI — la de la retromanía y el presque $v u$-, sean más que evidentes, esto no significa que lo retro no fuera protagonista en años anteriores o que estuviera ausente en las teorizaciones de los años noventa. Que hoy se haya exacerbado en la cultura popular, que se haya perfeccionado hasta límites insospechados mediante el caudal que le ofrece Internet y que todo ello cuestione el poder creativo del anacronismo, no quiere decir que éste no fuera tenido en cuenta anteriormente. Tampoco que no se sospechara, como decía Enzensberger en 1996, subrayando ya la pujanza de cierto anacronismo comercial, que «el anacronismo ha conocido días mejores, y que por añadidura amenaza con volverse anacrónico» ${ }^{22}$.

Eran los comienzos de la retromanía. Jameson aludía ya a la mode rétro del cine de la nostalgia. Más recientemente, Andreas Huyssen consideraba «el boom de la moda retro» como otro ejemplo del proceso de musealización global. El propio Huyssen, en publicaciones posteriores, ha continuado insistiendo en uno de sus lemas recurrentes, aquella «ofensiva del presente sobre el resto del tiempo» que mencionaba Alexander Kluge, a fin de subrayar que «las modas de reproducción retro hacen que cada vez sea más difícil reconocer lo que es genuinamente viejo

19 Zamora, J. A., «Dialéctica mesiánica: tiempo e interrupción en Walter Benjamin», en Amengual, G., Савот, M., y Vermal, J. L. (eds.), Ruptura de la tradición. Estudios sobre Walter Benjamin y Martin Heidegger, Madrid, Trotta, 2008, p. 110.

20 Didi-Huberman, G., Ante el tiempo, ed. cit., p. 142.

21 Huyssen, A., En busca del futuro perdido. Cultura y memoria en tiempos de globalización, trad. de S. Fehrmann, Buenos Aires, F.C.E, 2001, p. 7.

22 Enzensberger, H. M., "Acerca del hojaldre cronológico. Meditación sobre el anacronismo», en Enzensberger, H. M., Zigzag, trad. de M. Faber-Kaiser, Barcelona, Anagrama, 1999, p. 27. 
en una cultura de preservación y restauración». Quizá, en todo caso, el más sintomático fuera el propio Enzensberger, quien, al intuir esa progresiva afirmación del anacronismo comercial, señalaba: «las estrategias del saqueo cultural y de su comercialización adoptan nombres como retro, remake y recycling, aunque el entusiasmo por este mercadillo ideológico y artístico se mantiene dentro de unos límites ${ }^{23}$. Pues bien, serían esos límites los que se habrían resquebrajado. Y es que, en realidad, tales temas y autores, de un modo u otro y con unos fines $\mathrm{u}$ otros, percibían la emergencia de lo retro como un ejemplo más de un contexto mayor: las paradojas de la posmodernidad (Jameson), la hipertrofia de la memoria y la musealización global (Huyssen), el cuestionamiento de la idea de progreso (Enzensberger). La moda retro representaba, así, el elemento pop y juvenil, de cultura de masas, si se quiere, que acompañaba a temas para adultos, tan actuales, y tan antiguos, como el problema de los monumentos, el papel del museo, el «mal de archivo» o el olvido y la pérdida del futuro.

El cambio se produce cuando ese elemento juvenil se transforma en síntoma general: ¿por qué me va a interesar el pasado y la búsqueda de sus grietas si puedo acceder a él, a ellas, a través de Internet, y además contárselo a mis amigos? ¿Por qué me va a atraer el futuro si me basta, de hecho me sobra, con el presente? De nuevo, Simon Reynolds, comentando aquella idea de William Gibson según la cual el Futuro, con $\mathrm{F}$ mayúscula, no interesaría demasiado a las generaciones más jóvenes, lo ha explicado con total claridad: "La necesidad de escapar del aquí y ahora [...] es tan fuerte como siempre, pero se satisface con la fantasía (de allí la tremenda popularidad de las novelas y películas basadas en la magia, los vampiros, la hechicería y lo sobrenatural) o la tecnología digital. ¿Por qué habría de importarle a mi hijo cómo será el mundo en 2082 cuando ahora mismo, a pesar de habernos mudado recientemente a California, puede encontrarse con sus amigos de Nueva York en el ciberespacio?» ${ }^{24}$. Y es que, en todo caso, si esos amigos se entretuviesen con cualquier elemento futurista, no sería demasiado complicado profetizar que tal futurismo sería el del retrofuturismo, la versión más actual del steampunk original ${ }^{25}$. Los signos en la nueva moda son claros, y aludo sólo a algunos relativamente recientes: muestra de artilugios steampunk en el Museo de la Historia de la Ciencia de Oxford en 2009 con más de 80.000 visitantes; la exposición Steampunk comisariada por Elisabeth Roselló en el Museo de las Ideas y los Inventos de Barcelona en noviembre de 2012; la Primera Semana Retrofuturista en Barcelona en febrero de 2013; la reciente aparición de compilaciones: en 2012 Steampunk. Antología retrofuturista, en 2013 Steampunk cinema y Ácronos.

23 Respectivamente, cfr. JAmeson, F., "La lógica cultural del capitalismo tardío», en JAmeson, F., Teoría de la postmodernidad, trad. de C. Montolío y R. del Castillo, Madrid, Trotta, 1996, p. 40; Huyssen, A., En busca del futuro perdido, ed. cit., p. 18; Huyssen, A., Modernismo después de la posmodernidad, trad. de R. Filella y M. Abdo, Barcelona, Gedisa, 2011, p. 51; Enzensberger, H. M., "Acerca del hojaldre cronológico. Meditación sobre el anacronismo», ed. cit., p. 27.

24 Reynolds, S., Retromanía, ed. cit., p. 436.

25 Véase sobre el tema Hernández SÁnchez, D., «Steampunk romántico», en Notario Ruiz, A. (ed.), Contrapuntos estéticos, Salamanca, Ed. Universidad de Salamanca, 2005, pp. 121-133. 
Antología Steampunk ${ }^{26}$, etc., por no hablar de todo tipo de películas, cómics, blogs y más de un bestseller. Y es que el retrofuturismo, mediante su apropiación de la versión más light del steampunk clásico, lo tiene todo para ser un producto casi perfecto: pasado, presente, futuro, moda, toque juvenil, filosofía do it yourself... La conclusión es obvia: el futuro es retro.

Teniendo todo esto en cuenta, lo importante no sería que el anacronismo comercial haya devenido retromanía o retrofuturismo y que, inocentemente, deseemos seguir alejándolo de un anacronismo "para adultos». Sería mejor decir que, si aún desean mantener cierta fuerza operativa, el anacronismo y su creación activa de memoria han de tener siempre presente la retromanía global, pues supone ésta uno de los contextos cotidianos donde se enmarcan aquéllos. Por supuesto, hay diferencias claras entre anacronismo y retromanía. Los caracteres del primero son conocidos, los del segundo quizá no tanto, aunque Reynolds los ha concretado bien: el pasado al que alude lo retro es un pasado inmediato, que se recuerda y reconoce, de hecho casi está sucediendo todavía —modernariato, llamaba Paolo Virno a tal carácter ${ }^{27}$-; este recuerdo es de una exactitud considerable —más que considerable: casi siempre puede accederse a él a través de Internet—; está vinculado especialmente con la cultura popular; no es un pasado "académico y serio", sino divertido, entretenido y, por supuesto, dispuesto a desprenderse de su singularidad para unirse a otros tiempos y disfrutar de su eclecticismo. Pero, si esto es así, ¿cómo conciliar con ese pasado accesible, amigable y social la seriedad trágica de la constelación anacrónica? ¿Hemos de esperar a los biopics sobre el suicidio de Benjamin, sobre el de Carl Einstein, sobre el acceso a la locura de Aby Warburg? ¿O ya existen? Es más: ¿cómo conciliar la inoperante y alegre previsibilidad del presque vu con la extrañeza fantasmática que suscita todo déjà vu? ¿Cómo seguir pensando, con Agamben, que a lo contemporáneo se accede desde la inactualidad y el anacronismo, si tales intempestividades no pueden liberarse, ya no, de la retromanía generalizada, o sea, de la actualidad? Porque, si algo parece claro, ello es que de la retromanía, por ahora, no se percibe ningún indicio de final. Se trata de un elemento típico de época transicional, y las transiciones pueden ser muy largas. O dicho de otra manera: que la retromanía no puede evitarse, ni tampoco conviene despreciar su fuerza, pues, nos guste o no, corresponde a nuestro presente - otra cosa es que nos interese más o menos-. Con ello, el deseo de contemporaneidad de Agamben debe asumir que lo inactual está marcado, que el anacronismo no puede eludir su duplicación y que, por tanto, hay que ser cuidadosos si queremos continuar utilizándolos como modos de acceso al presente... y al pasado.

Por supuesto, podemos seguir valiéndonos del anacronismo y determinadas teorías del déjà vu o, por lo menos, de algunos de sus aspectos, pero su lectura ha de modificarse, a fin de fortalecerlos ante el acoso de la inevitable retromanía. Para ello, es posible ofrecer un modelo de intervención en esta nueva dialéctica que discurre entre el anacronismo y lo retro. Incluso es factible servirse de análisis previos a

26 Palma, F. J. (ed.), Steampunk. Antología retrofuturista, Madrid, Nevsky (Fábulas de Albión), 2012; VV.AA., Steampunk cinema, Barcelona, Tyrannosaurus Books, 2013; VV.AA., Ácronos. Antología steampunk, Barcelona, Tyrannosaurus Books, 2013.

27 VIRno, P., El recuerdo del presente. Ensayo sobre el tiempo histórico, trad. de E. Sadier, Buenos Aires, Paidós, 2003, p. 61 ss. 
la década re-, esas teorías que al comienzo aparecían en el contexto de la moda del anacronismo. Quizá resulte paradójico, incluso contradictorio con el trayecto seguido hasta aquí, pero interesa mostrar no sólo que el anacronismo todavía mantiene cierta efectividad, también que algunos de sus análisis siguen siendo útiles al colocarlos ante la situación retromaniaca. Y en todo caso, si nos ponemos quisquillosos, puede que la retromanía sea inevitable y global, pero también lo es el anacronismo, incluso de un modo mucho más explícito: sólo tenemos que acudir al código genético, a nuestro antiquísimo ropaje somático y psíquico, a la lentísima evolución de nuestra conciencia, para comprender que «el anacronismo no es un error evitable, sino una condición básica de la existencia humana ${ }^{28}$. Únicamente ha de adecuarse a la situación, y a sus nuevas características: la primera de ellas, comprender que el marco de acción del anacronismo no es ya sólo el pasado oculto o las grietas de la historia, sino también el pasado completamente visible, luminoso y actual reciclado por la cultura retro, el pasado pasado y el pasado presente, diríamos. O, de otro modo: el pasado recordado, inactual, y el pasado percibido, actualísimo. Es aquí donde podrían introducirse algunos elementos del análisis que lleva a cabo Paolo Virno.

El recuerdo del presente. Ensayo sobre el tiempo histórico ofrece una de las teorías más interesantes sobre el tema del déjà vu. Resulta, además, muy adecuada para la ocasión, pues es de las pocas que vincula déjà vu y anacronismo de un modo detenido. De hecho, lo que realmente interesa de la lectura de Virno en este momento es su interpretación de la simultaneidad de percepción y memoria — de ahí, claro, el final del párrafo anterior- que postulaba Bergson. Análisis correctos, quizá demasiado, sobre la memoria en las sociedades actuales, como el de Huyssen, tienden a mantener bases comunes: la memoria supondría un anclaje que nos sostiene ante el carácter inestable de la temporalidad, un tiempo fuera de quicio cuyas modalidades se fusionan o se separan a toda velocidad y de un modo apenas controlable. De lo que se deduce una conclusión obvia: «si estamos sufriendo de hecho un excedente de memoria, tenemos que hacer el esfuerzo de distinguir los pasados utilizables de aquellos descartables» ${ }^{29}$.

El problema, claro, es que tal proceso de distinción no es tan sencillo -en ningún contexto- - , redirigiéndolo hacia nuestro asunto, a la retromanía no le interesa demasiado: para ella, nada hay descartable, todo es nuevo, como para cualquier memoria absoluta. Además, no ha de olvidarse que la innovación no opera con «cosas», sino con valores, o, más exactamente, con su transmutación: «la innovación no consiste en que comparezca algo que estaba escondido, sino en transmutar el valor de algo visto y conocido desde siempre» ${ }^{30}$. Siendo esto así, los juegos de descartes que mencionaba Huyssen y para los que solicitaba nuestro esfuerzo son secundarios: se nos darán hechos. Por ello, la clave no se encuentra en un proceso de distinción entre pasados, sino en sus modos de acceso, o, en nuestro contexto, entre tipos de anacronismo. Y no para distanciar el anacronismo «para

28 Enzensberger, H. M., «Acerca del hojaldre cronológico. Meditación sobre el anacronismo», ed. cit., p. 13.

29 Huyssen, A., En busca del futuro perdido, ed. cit., p. 39.

30 Groys, B., Sobre lo nuevo. Ensayo de una economía cultural, trad. M. Fontán, Valencia, Pre-Textos, 2005, p. 19. 
adultos» del anacronismo comercial, sino para delimitar los efectos de los que el teórico italiano denomina anacronismo formal y anacronismo real.

Virno inicia su análisis del déjà vu y, con él, del tiempo histórico, acudiendo al que había dedicado Bergson al mismo fenómeno, especialmente en el ensayo de 1908 "El recuerdo del presente y el falso reconocimiento». De hecho, el núcleo de la argumentación de Virno se basa en distinguir entre recuerdo del presente y falso reconocimiento. Para Bergson, y Virno con él, la formación del recuerdo no es posterior a la percepción, sino que se dan simultáneamente. Lo percibido, desde el inicio, queda marcado por la posibilidad de su recuerdo, con lo que el síntoma típico del déjà $v u$, ese extraño recuerdo del presente, sería precisamente el que permite que haya memoria. La vida, la acción, la praxis, privilegian la percepción, evidentemente, y no su inútil réplica, con lo que «desaparece así de la escena el hecho basal: que nos acordamos de aquello que sucede mientras sucede». A partir de tal lectura, todo presente queda, a la vez, fijado como real, mediante su percepción, y como pura potencialidad, pura virtualidad, a través de su simultáneo recuerdo, con lo que se establece un anacronismo sistemático, utilizando los términos de Virno, que vincula de modo explícito potencia y memoria. Es este anacronismo el que permite hablar de sus dos figuraciones, siempre antitéticas: un anacronismo formal, que aplica el pasado al presente, la posibilidad de su recuerdo, y, por tanto, lo sitúa en un pasado en general, y un anacronismo real, donde el pasado es reducido a un hecho pasado. Si el primero circunscribe el pasado a la experiencia de lo posible, el segundo lo conduce a un hecho sucedido, un punto de la secuencia cronológica. Así, esta potencialidad, este ser-posible que, con Aristóteles y Agustín, Virno encuentra a la base de toda percepción precisamente por suceder ésta a la vez que su recuerdo, es lo que se define como perenne inactualidad, como inactualidad del tiempo total, un "persistente no-ahora contra el cual se recortan los diversos hic et nunc»: una inactualidad duradera, permanente, que, por tanto, sólo puede ser objeto de la memoria.

Cada acto, cada presente, tiene, entonces, un pasado doble, el de las actualidades que lo preceden y en cierto modo lo causan, y un pasado indefinido, el de esa potencia, anacrónica e inactual, esa facultad de lo posible, que siempre permanece. Así, dice Virno, el recuerdo se bifurca, pues remite tanto a actualidades pasadas como a la persistente potencia: «el recuerdo de un acto reproduce la percepción que se tuvo cuando él se realizó; representa a aquel que ha estado presente en un momento transcurrido; permite reconocer un ente o una acción ya aprehendidos en otra ocasión. El recuerdo de la potencia, por el contrario, no se basa en una percepción previa: concierne a algo (un "antes" puro, el horizonte de la anterioridad, el pasado en general) que no habiendo sido nunca presente, se deja solamente rememorar» ${ }^{31}$. En este sentido, podría, entonces, aplicarse la teoría de Virno al pasado que revisita la retromanía y al pasado sobre el que ejerce su efecto el anacronismo. El primero se situaría junto al anacronismo real: su pasado, el de todo elemento retro, se recupera de modo directo y es fácilmente apresable. No deja restos ni rastros, pues se trata de un hecho concreto del pasado, casi percibido al no ser nunca muy

31 VIRno, P., El recuerdo del presente. Ensayo sobre el tiempo histórico, ed. cit., p. 21, p. 76 y p. 131, respectivamente. 
grande la distancia con su presente. Por ello, se versiona de un modo invasivo y no causa mayores consecuencias en su actualización. No resultaría demasiado problemática, entonces, la pesada, en ocasiones entretenida, retromanía, pues no modifica sus pasados, por mucho que los haga presentes. Son machacones, sí, pero no productivos. De hecho, si ese gesto pasado desaparece al ser convertido en retro, es que no merecía mucho más.

El pasado del anacronismo, por contra, remitiría al pasado en general del anacronismo formal. A esa perenne inactualidad, a ese persistente no-ahora que sólo puede ser objeto de memoria y se constituye como pasado productivo. Por eso, sólo cuando el pasado se deja únicamente rememorar, que no "percibir» —es decir, «revisitar»—, hace tiempo e historia. Sólo cuando la inactualidad se mantiene como tal, duradera y permanente, nunca controlable y, por tanto, nunca actual, retro, es posible hablar de la historicidad del anacronismo. Atravesados por sus leves gestos, por la tenue distancia que nos conceden la inactualidad y el anacronismo, podremos ser contemporáneos, incluso disfrutar —o no- de la, por ahora, obsesiva retromanía. Otra posibilidad sería, por supuesto, forzar más aún la lectura de Virno, si tenemos en cuenta que el presente, el acontecimiento, el acto, dejan de ser hoy ámbitos de la percepción para desaparecer gustosos en el puro recuerdo de la imagen souvenir o, lo que viene a ser lo mismo, carnaza para la construcción de un relato. En efecto, como decía Virno, con Bergson, percepción y recuerdo se dan simultáneamente, pero el contexto ya no es el de la extrañeza del déjà $v u$, sino el de la cotidianeidad de un presente cada vez más escamoteado por su propia representación: falsos reconocimientos, sí, aunque ahora de modo literal. 